\title{
Enemigo a las puertas. La libertad política y los principios fiduciarios en el socialismo británico
}

\author{
The Enemy at the Gates. Political Freedom and Fiduciary \\ Principles in British Socialism
}

JULIO MARTÍNEZ-CAVA AGUILAR*

\begin{abstract}
Resumen. El objetivo de este artículo es proporcionar algunas claves históricas y conceptuales para comprender la historia del socialismo británico libertarian y su relación con la concepción fiduciaria del poder político y del poder económico. Las expresiones de este socialismo no son homogéneas, convivieron con otras ideas rivales llegando en ocasiones a mezclarse con ellas; $\mathrm{y}$ fueron formuladas siempre como respuestas concretas ante los problemas que planteaba cada momento histórico. Desde el socialismo republicano de algunos seguidores de Robert Owen hasta los desafíos que planteó la New Left, las teorías fiduciarias encontraron hueco para abrirse paso en los escritos de estos socialistas libertarian.

Palabras clave: socialismo libertarian, relaciones fiduciarias, propiedad, libertad.
\end{abstract}

\begin{abstract}
The objective of this paper is to provide some historical and conceptual keys to understand the history of libertarian British socialism, and its relationship with the fiduciary conception of political power and economic power. The expressions of this libertarian socialism are not homogeneous, they coexisted with other rival conceptions, sometimes mixing with them. Those articulations were always formulated as concrete responses to the problems laid out by different historical moments. From the republican socialism of some Robert Owen's followers to the challenges exposed by the New Left, fiduciary theory found room to break through in the writings of these libertarian socialists.
\end{abstract}

Key words: Libertarian Socialism, Fiduciary Relationships, Property, Liberty.

Recibido: 16/05/2020. Aceptado: 24/06/2020. Cómo citar este articulo: Martínez-Cava, J. (2020). Enemigo a las puertas. La libertad política y los principios fiduciarios en el socialismo británico. Daimon. Revista Internacional de Filosofía, (81), 161-177. https://doi.org/10.6018/daimon.428181

* Investigador predoctoral en el Departamento de Sociología de la Universidad de Barcelona. Contacto: juliomartinezcava@gmail.com. Líneas de investigación: historia del pensamiento y filosofía política republicana, historia del socialismo, marxismo británico, clases sociales. Publicaciones recientes: Martínez-Cava, J. "Erik Olin Wright como rara avis. Balance del 'último' marxista analítico”, Res Publica, 21(2), 2018, pp. 333-352; Martínez-Cava, J. "Introducción”, en E. P. Thompson, Costumbres en común. Estudios sobre la cultura popular, Madrid, Capitán Swing, 2019, pp. 11-45. 


\section{Introducción ${ }^{1}$}

La historia del pensamiento político no se deja ordenar fácilmente con etiquetas, aunque la inevitabilidad de su uso confiere a estas un atractivo galvanizador que tiende a llevarnos a no pocas confusiones. Por esa razón estamos obligados a abordar el estudio de los conceptos políticos siempre enraizados en su contexto histórico, atendiendo a las intenciones con que son empleados, y registrando los desplazamientos semánticos que pueden ocurrir en su seno (Dunn, 1968; Pocock, 1971). En ocasiones, una misma idea puede ser despojada de sus antiguos ropajes y ser expresada por otros cauces lingüísticos. En otras, el mismo término puede haber variado tanto su significado que perdamos de vista su sentido original, enturbiando nuestra comprensión del pasado. De poco hay que sorprenderse: la historia de las ideas políticas se parece menos a la elegante sucesión de taxonomías hieráticas del escaparate de un herbolario que a los bestiarios mestizos con los que nos deleitaba Borges.

La concepción de la libertad en la tradición socialista británica es un buen ejemplo de ello. En ella convivieron, a veces mezcladas y a veces en abierta pugna, diferentes formas (no todas compatibles) de comprender la relación entre el individuo, la propiedad y el Estado. Una de estas formas, que en adelante llamaré libertarian, se caracterizó por su rechazo de lo que se conoció como "socialismo de Estado" (State Socialism), al cual oponía sus propias ideas sobre los derechos individuales y un pluralismo jurídico en la organización de la propiedad. Al mismo tiempo, esta corriente lidió con algunas tendencias antipolíticas, defendiendo la necesidad de mantener la existencia de un Estado central y unas instituciones parlamentarias, eso sí, fiscalizadas y controladas democráticamente. En ese espacio delimitado por ambos extremos, los socialistas libertarian buscaron diferentes maneras de controlar al Estado y al Parlamento, recurriendo en no pocas ocasiones a la concepción fiduciaria del poder político. Según esta concepción, la autoridad pública no justifica por sí misma su posición de poder, sino que se crea en régimen de fideicomiso (trust): debe su existencia a un "Principal" que la elige en tanto que servidora pública o "Agente" (trusteelagent), razón por la cual está obligada a cumplir con los intereses del Principal y a rendir cuentas ante este (Criddle y Fox-Decent, 2018). Lo que interesó a los socialistas de este esquema -dado el siempre existente margen de discrecionalidad del Agente- son las posibilidades que ofrece para articular mecanismos efectivos de control y dispersión del poder. Como consecuencia de todo ello, el hilo socialista libertarian terminó por formular su propia concepción de la libertad política.

En este artículo analizo algunos episodios fundamentales (en absoluto todos) de esta historia y ofrezco algunas claves teóricas para comprenderla. En primer lugar, trato de poner en cuestión el consenso que existe actualmente en el mundo académico en torno al concepto "libertarian". Posteriormente, repaso distintos momentos históricos del socialismo británico desde su creación con el owenismo hasta llegar al pensamiento de algunos teóricos

1 El presente trabajo se ha llevado a cabo en el marco del proyecto de investigación Libertad política, derechos de propiedad, bienes comunes y política pública entendidos como relaciones fiduciarias (PGC2018-094324-BI00), financiado por el Ministerio de Ciencia, Innovación y Universidades (MCIU), la Agencia Estatal de Investigación (AEI) y el Fondo Europeo de Desarrollo Regional (FEDER). Jordi Mundó y David Guerrero tuvieron la amabilidad de corregir un borrador previo de este artículo y hacer algunas sugerencias. La responsabilidad sobre el contenido final, sobra decirlo, es solo mía. 
de la New Left, momentos en los que las ideas libertarian tuvieron un peso especial en esta tradición. Al final del artículo se ofrecen algunas conclusiones.

\section{Los usos de "libertarian” en el pensamiento político británico}

En el contexto anglosajón contemporáneo el término "libertarianism" se emplea por lo general para referirse a la tradición liberal en su defensa de los derechos individuales inalienables (entre los que ocupa un destacado lugar el derecho a la propiedad en un sentido exclusivo y excluyente), como el valor máximo a proteger frente a su principal amenaza: el Estado. Según el vicepresidente ejecutivo del Cato Institute, David Boaz, esta tradición libertarian incluiría una determinada ontología social que confía en los "órdenes espontáneos" (de forma preeminente, el intercambio mercantil) y que sostiene nociones de "autopropiedad" à la Nozick. En algunas ocasiones, su longevidad se remonta hasta los orígenes del liberalismo político, confundiéndose con este, por lo que sus máximos expositores serían Locke, Smith o los Founders norteamericanos (Boaz, 2020), mientras que en otras ocasiones se restringe el alcance de esta tradición a una parte de la tradición liberal, ya en los siglos XIX y XX, y los autores destacados pasarían a ser Spencer, Spooner, Rand, Rothbard o Nozick (Mack, 2011) .

Algunos filósofos contemporáneos, críticos con esta corriente, parecen inclinarse por esta segunda posibilidad. Para Philip Pettit, por ejemplo, el término libertarian designa esa parte de la tradición liberal que no reconoce otro valor político aparte de la libertad negativa; frente a otras alternativas, como el liberalismo de John Rawls, que verían la libertad negativa como un desiderátum entre otros $(2004,118)$. Guy Standing sostiene que esta tradición se define por su defensa de que "cada individuo tiene o debería tener autopropiedad, y por lo tanto no tiene ningún deber de servicio para con los demás, excepto los derivados de su propia acción voluntaria" (2018, 31). Para Eric MacGilvray, un libertarian es una persona que "favorece la extensión de las normas y prácticas del mercado a prácticamente todas las áreas de la vida" $(2011,1)$.

En suma, aunque la extensión del concepto está poco clara y sigue debatiéndose qué autores o períodos cubre, parece que hay un cierto acuerdo académico entre filósofos e historiadores del pensamiento en cuanto a su intensión o core definition ${ }^{4}$. Ser libertarian implicaría:

2 He decidido no traducir al castellano el término libertarian porque las dos opciones disponibles me parecen confusas para lo que discutiré aquí: "libertario" en lengua castellana remite a la tradición anarquista, y "libertariano" acostumbra a mentar a una escuela filosófica determinada (Nozick, Rothbard, etc.). Algunos usos que mencionaré desbordan y hasta contradicen estos sentidos.

3 Un hito importante en esta reconstrucción tuvo lugar en 1965 con la publicación de una selección de escritos de los whigs radicales Thomas Gordon y John Trenchard con el título The English Libertarian Heritage (David L. Jacobson, comp., Indianapolis, Bobbs-Merrill) que incluía un prólogo de Ronald Hamowy. Boaz ha querido estirar todavía más sus raíces hasta los panfletos levellers. Estos esfuerzos no están exentos de tensiones si tenemos en cuenta que los republicanos también han reivindicado el legado de Gordon y Trenchard (Pettit, 1999, 276) o que la tradición política liberal, estrictamente hablando, no echaría a andar hasta el siglo XIX, aunque pudiera haber visto desarrolladas algunas ideas en décadas anteriores sin haberse articulado todavía como "liberalismo" (Díez del Corral, 1956; MacGilvray, 2011, 23). Para una interpretación alternativa de Locke incompatible con la filosofía de Nozick puede consultarse (Mundó, 2005).

4 Puede verse este acuerdo tácito entre investigadores de distintas filiaciones filosófico-políticas en las menciones aparecidas en el Oxford Handbook of Political Theory (2006). 
i) tratar de salvaguardar ciertos derechos individuales, especialmente el derecho de propiedad, frente a las interferencias arbitrarias de los Estados (para lo cual se proponen modelos de "gobiernos limitados" o, en las versiones anarco-libertarian, sencillamente la disolución del Estado);

ii) confiar en la eficacia de los órdenes autorregulados que surgen espontáneamente de la vida en sociedad, en particular los intercambios mercantiles que se postulan como la mejor institución para mediar las relaciones humanas;

iii) sostener un individualismo moral, que deja los deberes sociales y el sentido de comunidad al albur de los contratos voluntarios que puedan suscribir las partes.

Un rasgo compartido de las aproximaciones anteriores es que son posteriores a los años 70 del pasado siglo XX, coincidiendo con el final del Pacto Social de posguerra. No es casualidad que la publicación de Anarchy, State and Utopia de Nozick se produjera en 1974, y en 1977 se fundase el Cato Institute y Rothbard crease la Journal of Libertarian Studies.

Sin embargo, es evidente que el concepto es polisémico, y este uso se ha visto obligado a convivir con otros significados emparentados: libertarian ha seguido empleándose para hablar de la tradición anarquista ${ }^{5}$; para definir a una persona que cree que el Estado no debería poner límites a las libertades del individuo ${ }^{6}$; o para denotar el carácter antiautoritario de los nuevos movimientos sociales originados en los años 60 (así lo emplean, por ejemplo, Dworking, 1997, 125; o Hobsbawm, 2002, 267).

Y el problema no ha hecho más que comenzar. En su compilación de los panfletos revolucionarios de los levellers, Don $\mathrm{M}$. Wolfe utiliza el adjetivo libertarian para describir los procedimientos de petición al Parlamento como un mecanismo democrático empleado por Lilburne y sus socios (Wolfe, 1944, 71) ${ }^{7}$. Aquí el concepto se emplea en un sentido diferente a los ya explicados. Wolfe se refiere a una concepción anglosajona de las libertades individuales inalienables que se diferencia de las anteriores en dos frentes. Por un lado, frente a los usos anarquistas o antiautoritarios, no implica el objetivo de abolir el Estado o el Parlamento y va más allá de ser una mera disposición reacia ante el poder central. Por otro lado, frente a los right-libertarians, no conlleva la defensa de órdenes espontáneos autorregulados, de derechos de propiedad exclusivos y excluyentes o de un individualismo moral. En este tercer sentido, las ideas libertarian remiten a la idea del "freeborn Briton" (Torr, 1956, 105) y se solapan con los movimientos democratizadores que buscaban modificar, regular o redistribuir la propiedad, como los propios levellers en

5 Peter H. Marshall recuerda que de los usos políticos del término, este es el más antiguo, y localiza una primera mención en 1858 por parte del anarquista Joseph Dejacque que decidió titular a su diario Le Libertaire, Journal du Mouvement (Marshall, 1998, 641). Existía un sentido metafísico y no político antes, para referirse a los defensores del libre albedrío frente a los deterministas o necessitarians (Sprading, 1913, 5).

6 La miscelánea obra de Charles T. Sprading, Liberty and the Great Libertarians publicada en 1913, puede ser un buen ejemplo. En ella se encuentra la idea de que las nociones libertarians eran compartidas por diferentes tradiciones políticas, e incluía entre sus grandes autores a personajes que pondrían algo de color en las mejillas del Cato Institute: Henry George, William Godwin, Edward Carpenter, George Bernard Shaw, Francisco Ferrer i Guardia, Mijail Bakunin o Emma Goldman (Sprading, 1913).

7 Agradezco esta referencia a David Guerrero y su profuso conocimiento del período. 
la Revolución inglesa o los radicales seguidores de Tom Paine a finales del XVIII (Kennedy, 2013; McCann, 1997, 81).

Para algunos autores este último significado del término, con sus referentes democráticos y su propia simbología (particularmente el cap of liberty o gorro frigio ${ }^{8}$ ), se alarga en el tiempo llegando incluso a confluir con el anatema de los right-libertarians... jla tradición marxista! En un artículo de 1979, titulado "Recovering the libertarian tradition" y publicado en la revista Leveller, el historiador E. P. Thompson sostenía:

Yo no comparto la idea de que la tradición marxista es anti-libertarian. He argumentado en profundidad que los primeros marxistas en este país, dentro de los cuales estaba William Morris, eran profundamente libertarian. Lo que es indignante, algo que la mayoría de la tradición marxista ha permitido que ocurra, es la confiscación de la idea de democracia de nuestro movimiento (Thompson, 1979).

A la vista de lo anterior, no parece arriesgado asumir que en las últimas décadas se habría producido un desplazamiento semántico, manteniéndose constante el uso cotidiano antiautoritario, pero quedando sepultado el sentido democrático en favor del "neoliberal". A mediados de los 70, Murray Rothbard podía escribir con placer poco disimulado:

Un aspecto gratificante de nuestro ascenso a una posición de cierta importancia es que, por primera vez en mi memoria, nosotros, "los nuestros", habíamos capturado una palabra crucial del enemigo. Otras palabras, como "liberal", se identificaron originalmente con los libertarios del laissez-faire, pero habían sido capturadas por los estatistas de izquierda, lo que nos obligó en la década de 1940 a denominarnos a nosotros mismos, de una forma débil, como liberales "verdaderos" o "clásicos". Libertarian, por el contrario, había sido durante mucho tiempo una mera palabra cortés para los anarquistas de izquierda, es decir, para los anarquistas que estaban en contra de la propiedad privada, ya fuesen de tipo comunista o sindicalista. Pero ahora nos hicimos con el concepto $(2007,83)$.

8 La simbología libertarian, en particular el uso del gorro frigio, nos ofrece algunas pistas para nuestra historia. El origen del conocido gorro rojo tejido con lana se remonta hasta el Mediterráneo antiguo, donde simbolizaba la adquisición de la condición de libre por parte de un antiguo esclavo o siervo, como quedaría registrado, por ejemplo, en múltiples monedas romanas que tenían grabado el pileus (Stevenson, 1889, 629). Su empleo en el Reino Unido comenzó de forma tardía. A lo largo del siglo XVI este símbolo fue utilizado con frecuencia en las Provincias Unidas contra la dominación el Imperio español, por eso fue Guillermo de Orange el responsable de su introducción en Inglaterra tras la Revolución Gloriosa. En el siglo XVIII británico eran comunes las representaciones de una mujer que encarnaba el espíritu patrio, Britannia, con la Carta Magna en una mano, la balanza de la justicia en la otra, y el gorro frigio sobre su cabeza (asociado al lema "Liberty or Death!"). Cuando comenzó la Revolución francesa y los sans-culottes adoptaron este símbolo como propio, las élites británicas empezaron a disociarse de él: tras la ejecución de Luis XVI quedó vinculado al "jacobinismo francés" y a la "anarquía" y solo algunos radicales lo seguirían usando, especialmente los seguidores de Thomas Spence. El gorro frigio reaparecería tras las guerras napoleónicas en todas las manifestaciones radicales posteriores a 1815 y en muchos mítines cartistas, y lo haría, de nuevo, como un símbolo patrio (Epstein, 1989). 
El argumento de Rothbard no debe llevarse demasiado lejos. Se pueden encontrar usos recientes de libertarian diferentes a los empleados por el Cato Institute, el Mises Institute, la Encyclopaedia Britannica o los Oxford Handbooks que no se compadecen fácilmente con el triunfalismo de Rothbard (véase, por ejemplo, Blaazer, 1992, xi; Goodway, 2006; Screpanti, 2007, x). Por lo tanto, asumiendo como hipótesis un desplazamiento semántico (no absoluto) en el concepto libertarian, en lo que sigue trato de exponer cómo una parte de la tradición socialista británica puede ser entendida a la luz de ese significado democrático (parcialmente) marginado. Aunque probablemente hoy en día estos libertarian socialists serían despachados con rapidez como "comunitaristas" en más de un departamento de filosofía, su estudio puede ser particularmente útil para la historia del pensamiento político, obligándonos a revisar algunos marcos de pensamiento heredados.

\section{Los orígenes (antipolíticos) del socialismo}

El impacto que tuvo la derrota del ala plebeya de la Revolución francesa llevó a muchos radicales británicos a pensar que la common people no estaba lista para el autogobierno político. El origen de la tradición socialista británica está vinculado a este hecho tanto como a la distancia que algunos radicales tomaron respecto al proyecto radical de la reforma, tratando de escapar del ambiente represivo de persecución política, limitación al derecho de asociación (Combination Acts, 1799-1824) y suspensión del habeas corpus con los que el gobierno de Pitt respondió al radicalismo de la década de $1790^{9}$. El socialismo británico, por tanto, nació como un movimiento paradójico de reformadores que renegaban de la reforma, como una respuesta "antipolítica" o de plena desconfianza hacia la política oficial (Cole, 1975a [1952], 11). Asociado con la figura de Robert Owen y su movimiento de comunas cooperativas, el apelativo "socialista" -en prensa desde al menos 1827-vino a significar el proyecto de realizar primero una gran "reforma moral" que permitiese posteriormente la reforma política. En términos generales, hasta 1848 "socialismo" y "owenismo" funcionaron casi como sinónimos (Claeys, 1989, 60, 192).

Esta tendencia antipolítica de Owen y de algunos de sus seguidores tenía también otras raíces. Su proyecto social recibió la impronta de los predicadores milenaristas, de las comunidades cuáqueras y de algunos filósofos como William Godwin. Aunque provenientes de orígenes bien diversos, estos elementos compartían el ideal de una sociedad a pequeña escala con base en las parroquias, donde la dependencia moral de cada individuo respecto a la comunidad serviría como un medio de asegurar la corrección de conducta de los ciudadanos, pudiendo prescindirse entonces de la clase política, de los soldados, abogados, curas, etc. Los conflictos sociales se reducirían y los que apareciesen podrían ser gestionados sin coerción (Claeys, 1989, 2, 30-49). La plasticidad de la naturaleza humana fue encumbrada por Owen y su teoría del medio social como determinante absoluto del carácter. Owen expresó esta visión a la perfección en el tercer Congreso Cooperativo de 1832:

9 Una represión que, como explicó Thompson, selló la alianza de algunos sectores radical-jacobinos con el primer movimiento obrero (Thompson, 2012 [1963], 127-214, 546). 
Con frecuencia se descubrió que los gobiernos despóticos eran mejores que los que se denominan como democráticos. En los países donde existían esos gobiernos, las clases laboriosas [industrious classes] no se encontraban en tanta miseria e indigencia como en su país; y, por lo tanto, en base a esto, no existía razón alguna para renunciar a los despotismos. En lo que respecta al sistema cooperativo, es irrelevante si los gobiernos eran despóticos o no (citado en Claeys, 1989, 72) ${ }^{10}$.

Tomando pie en sus teorías, Owen se embarcó en sus proyectos de comunidades cooperativas. La comunidad de New Lanark (Escocia) creada en 1800, implantó un sistema de autogobierno indirecto en el que los cabezas de familia elegían a unos representantes, que a su vez elegían a los jueces que llevarían todos los asuntos de la comunidad. Algunos seguidores empezaron a reclamar más democracia interna, denunciando que las comunidades se gobernaban "despóticamente". En la tensión entre las formas de gobierno paternalistas experimentadas por Owen y las demandas democratizadoras de algunos de sus seguidores se encuentran los primeros pasos de las ideas libertarian en el movimiento socialista.

Ya desde finales de los años 1820 algunos socialistas como William Thompson, William Lovet o James Bronterre O'Brien trataron de conciliar la filosofía social de las cooperativas con las demandas del movimiento radical, dando lugar a lo que James Napier Bailey llamaría un "socialismo republicano": "todo verdadero socialista, si desea lo mejor para su país y para el mundo, debe ser un radical y un socialista en sus principios" (Model Republic, n. 3, 1 de marzo de 1843, citado en Claeys, 1989, 237). En esta confluencia de ideas, comenzaron a aparecer los principios fiduciarios: la defensa del sufragio universal fue, como lo había sido en el radicalismo democrático, una manera de entender fiduciariamente el poder político -cuando se defendió como una forma para hacer responsable al poder del Estado (y no meramente como un medio de conquista del poder)- aunque no siempre compareciera en los precisos términos del lenguaje fiduciario anglosajón (trust - trustee).

La novedad de estos cooperativistas, respecto al radicalismo, es que ahora ofrecían un diagnóstico diferente de la fuente de los males a remediar: su enemigo ya no serían las "clases ociosas" que no permitían la representación plena del pueblo y cuyos impuestos excesivos impedían que el trabajador se apropiase del "fruto completo de su trabajo" [the full enjoyment of the produce of labour]; el enemigo ahora serían las clases "no-productivas" (entre las que se contaban los capitalistas, trabajasen o no) que bloqueaban la necesaria reforma de una sociedad cuya producción se orientaba a la producción del beneficio y no del uso. Ese diagnóstico exigía soluciones nuevas, y los socialistas republicanos se apresuraron en ofrecerlas, conectando conceptualmente el cooperativismo con las viejas ideas radicales. Lovett podía dirigirse a sus socios en los siguientes términos:

10 Esta tendencia antipolítica emergería una y otra vez en la tradición socialista (no solo la británica). Como explica John Dunn, no se trata de que la mayoría de socialistas renunciasen a la representación política, sino que su pensamiento se vio debilitado por la tensión entre esta y su preferencia por la participación cívica y la democracia directa por parte de las clases populares, ante la experiencia histórica de su opresión política (Dunn, 1984, 21). Parece que, en ocasiones, el precio a pagar por mantener la guardia alta contra el Estado fue un exceso de confianza en la plasticidad de la naturaleza humana. 
Con respecto a la igualdad de poder, los cooperativistas conciben que el poder para gobernar o para castigar a todos debe ser delegado por todos [delegated by all]; de lo contrario, prevaleciendo el sentimiento egoísta, la sociedad pronto será llevada a un estado (...) en el que una de las partes se volverá tan opulenta como para poder comprar a la otra, y la otra tan pobre como para venderse ("Report of the Second Quarterly Meeting of the Society for Promoting Co-operative Knowledge", 1829, citado en Claeys, 1989, 177).

En paralelo a estas evoluciones, la primera ley de reforma de 1832 que consolidó el poder de las clases medias facilitó la alianza de algunos cooperativistas y radicales con el movimiento obrero de las trade unions. En los debates de la Grand National Consolidated Trade's Union pueden rastrearse las huellas del lenguaje fiduciario:

De todas las grandes e importantes empresas públicas, el gobierno y solo el gobierno, como fiduciario [trustee] de la nación, debería ser el único propietario, así los impuestos podrían ser reemplazados por las ganancias legítimas que deberían acompañar al empleo de la riqueza nacional e individual (Official Gazette of the Trade's Unions, 1834, citado en Claeys, 1989, 313).

Estas ideas, sin embargo, fueron minoritarias en el movimiento cooperativo hasta 1848. Después de ese ciclo de revoluciones, la mayoría de los socialistas ya veían el problema del poder político de una forma parecida a como lo expresó años antes G. A. Fleming, que comenzaba citando a $\mathrm{O}^{\prime}$ Brien:

'Haga que su poder deliberativo y electivo sea lo más grande posible; haga que su poder administrativo y ejecutivo sea lo más pequeño posible: no me importan las pocas manos a las que confía estas funciones, mientras sean elegidas popularmente y estén sujetas a revisión y revocación por el organismo que las nombra'. Esto expresa con bastante precisión nuestra teoría del gobierno, y es esencialmente una democracia, en la cual la gente gobierna en su conjunto a través de los oficiales más sabios que pueden seleccionar (New Moral World, 1840; citado en Claeys, 1989, 319).

\section{El revival socialista de finales del XIX}

Tradicionalmente se ha tendido a considerar que el socialismo británico desapareció de la escena pública desde la derrota del cartismo a principios de los años 50 hasta el revival de la década de los 80 del siglo XIX (Cole, 1975a [1952], 159). Pero fue justamente en ese período en el que se constituyó la Asociación Internacional de Trabajadores (1864), cuyo influjo sería decisivo en las décadas siguientes. Un episodio merece nuestra atención aquí: en el congreso de Lausana de 1867 se aprobó una resolución en la que se puede leer: "1) que la emancipación social de los trabajadores es inseparable de su emancipación política; 2) que el establecimiento de libertades políticas es una primera medida de absoluta necesidad" (véase el capítulo 8 de la obra del historiador y revolucionario ruso Stekloff, 1928). El socialismo moderó así su tendencia antipolítica. 
En cualquier caso, es cierto que el movimiento socialista no volvió a ser un movimiento de masas hasta la década de 1880, cuando se fundaron la Federación Socialdemócrata o FSD (1881), la Liga Socialista como escisión de esta (1884), la Sociedad Fabiana (1884) y el Partido Laborista Independiente o ILP (1893), un hecho que tuvo lugar en paralelo a la transformación del Estado "manchesteriano" en el monstruoso aparato burocrático-imperialista de finales de la era victoriana.

La Federación Social-Demócrata estuvo liderada por Hyndman, un líder terco y poderoso que gestionó su poder con carácter dictatorial. Hyndman, como algunos socialistas alemanes, puso más énfasis en la conquista del poder estatal como principal y casi única solución (lo que vino en llamarse State Socialism, aunque su traducción institucional no estaba clara en absoluto). A pesar de esto, la FSD sirvió como una plataforma influyente para la formación de algunos futuros líderes del Partido Laborista con ideas bien diferentes, como Tom Mann (Foote, 1997, 23). Tom Mann estaba especialmente vinculado a las luchas sindicales del norte del país y acabaría siendo uno de los fundadores del ILP, donde su socialismo encontró una formulación libertarian (Torr, 1956). En el panfleto The Miner's Next Step (1912), por ejemplo, se revolvería contra el State Socialism al defender que "el Estado no sería un amo menos tirano que el propietario privado de las minas de carbón, de hecho sería más poderoso" (citado en Cole, 1975b [1954], 231).

Por su parte, la Sociedad Fabiana tampoco fue especialmente homogénea en sus ideas respecto al poder. En un primer momento los fabianos no apostaron por la propiedad del Estado como modelo de empresa ideal (Blaazer, 1992, 46), en su opinión las empresas socialistas deberían estar gestionadas por organismos locales elegidos democráticamente y careables por la ciudadanía (Cole, 1975b [1954], 118-119). No obstante, una rama del fabianismo empezó a desarrollarse en una línea anti-libertarian: frente al pensamiento de Sidney y Beatrice Webb, que no dejaron de defender la necesidad de controles democráticos sobre los representantes, Bernard Shaw llegó a admirar a aquellos gobiernos despóticos que delegasen en técnicos expertos. Esta obsesión por la epistocracia ${ }^{l l}$ prevalecería en la Sociedad Fabiana con el paso del tiempo, razón por la que "fabianismo" se volvería casi sinónimo de "tecnocracia" (Foote, 1997, 31). La fiscalización del poder acumulado pasó a un segundo plano, y para el Shaw de 1893, por ejemplo, se trataba de un problema de composición social:

Una Cámara de los Comunes formada por 660 gentlemen y 10 trabajadores ordenará al soldado que coja el dinero de los trabajadores para dárselo a los terratenientes. Una Cámara de los Comunes formada por 660 trabajadores y 10 gentlemen probablemente, a no ser que 600 sean idiotas, ordenará al soldado que coja el dinero de los terratenientes para dárselo a los trabajadores (Shaw, 1893, 24).

En contraposición con las propuestas de Hyndman se desarrolló el pensamiento político de William Morris, que empezó militando con la FSD pero que acabaría rompiendo en 1884 con lo que consideraba el "socialismo bismarckiano" de Hyndman y su "gobierno arbitrario" del partido. Morris fue también un crítico acérrimo de los fabianos, esos "socialistas blan-

11 Para esta noción véase (Estlund, 2008, 21-39; 206-222). 
dengues", a los que consideraba preocupados exclusivamente por la redistribución y no por la libertad (Thompson, 1988, 342 y ss.). Esto le llevó a fundar la Liga Socialista en 1894, donde colaboró con algunos socialistas antiparlamentarios y también con algunos anarquistas. Pero Morris no fue un anarquista: su sociedad ideal no era la reflejada en News from Nowhere, y por sus desavenencias con los libertarios rompió con la Liga en 1890 volviendo a colaborar con la FSD (Goodway, 2006, 22 y ss.).

¿Cuál era entonces el socialismo del gran artista del romanticismo? En su conferencia "La lucha de clases" de 1889 Morris subrayó, según reportó el Leeds Mercury, que "el socialismo era: que el pueblo trabaje para sí mismo y se administre a sí mismo, y que el Estado incorpore al conjunto del pueblo, y no esté compuesto de dos clases" (Thompson, 1988, 503). Parece cierto, sin embargo, que Morris consideraba que en el comunismo la maquinaria central del Estado desaparecería (excepto en las funciones mínimas e imprescindibles de producción y distribución), y consideró que la fiduciarización del poder no bastaría si no se combinaba con una descentralización masiva, dado:

el peligro de que la comunidad caiga en la burocracia, la multiplicación de departamentos y despachos y toda la parafernalia de la autoridad oficial; lo que, después de todo, es una carga, incluso cuando se ejerce por delegación del pueblo y de acuerdo con sus deseos ("True and False Society" en Morris, 2013 [1886], 236, cursivas nuestras).

Su denostación del parlamentarismo y su gran imaginación utópica le llevaron a revivir algunos de los impulsos antipolíticos de la tradición socialista, como cuando imaginó que en la futura sociedad comunista se podría prescindir de la necesidad de emplear funcionarios porque todo el mundo "arrimaría el hombro", que no existirían facciones ni "espíritu de partido", y que un gran "consejo del mundo socializado" regiría la coordinación necesaria para organizar la producción (Thompson, 1988, 632-633).

\section{El socialismo de entreguerras}

La Primera Guerra Mundial marcó un punto de inflexión importante en las aproximaciones al Estado. Las grandes potencias experimentaron por primera vez lo que era someter las economías de escala a la planificación y dirección estatal de forma masiva y continuada (Domènech, 2019, 235-237). Esto levantó las pasiones de muchos socialistas, que corrieron a abrazar formas más estatistas de socialismo, con la mirada puesta en una Rusia que ofrecía esperanzas. En Gran Bretaña, los representantes de esta nueva tendencia fueron los fabianos: después de 1914, por influencia de Emile Davis y H. G. Wells, se convirtieron en los fervientes defensores de la nacionalización (bajo formas tecnocráticas) frente a otros modelos de socialización de la propiedad (Cole, 1975b [1954], 209).

Para un pensador con enormes influencias libertarians como fue Harold Laski, el gran profesor de la London School of Economics (que llegaría a ser presidente del Labour Party), esto no podía ser sino una amenaza, así que dedicó varios ensayos a criticar la concepción de una soberanía "monista", esto es, irrestricta, que creía que se había extendido por toda 
Europa. En su lugar propuso distintos modelos de dispersión de aquella (Laski, 1917, 283). Ante la concentración de poder, público o privado, propuso un federalismo que:

no debe ser entendido en términos meramente espaciales. Se aplica tanto al gobierno de las minas como al gobierno de Irlanda o Massachussets. En último término sugiere no solo una división de la soberanía en términos de competencias sino también una revisión completa de la noción aceptada de propiedad (...) la libertad, en resumen, es incompatible con el sistema actual de la propiedad, porque lo que este provoca es una concentración de poder tal que inutiliza la personalidad política del ciudadano medio para cualquier propósito serio (Laski, 1921, viii-ix).

Laski acabaría compartiendo no solo el programa socialista de nacionalización de sectores estratégicos y la promoción de otras formas de propiedad, sino que propondría también "una base mínima de civilización para cada individuo con el objetivo de hacer posible su condición de ciudadanía" (Laski, 1922, 9). Por lo que su doctrina "implica, por decirlo así, la democratización del control industrial y la descentralización del poder político" (ibid., 10). Por otro lado, Laski combinó estos principios "federalizantes" con principios fiduciarios:

Un Estado debe, como regla general, actuar a través de agentes [agents] y ministros a los cuales se les ha confiado [entrusted] el ejercicio del poder. El poder así delegado [confided] puede estar limitado, como en América, o ser pleno, como en Gran Bretaña. Pero en ningún caso es de hecho más que un mero permiso para llevar a cabo los actos que puedan asegurarse la aprobación del público (Laski, 1921, 211).

De esta forma, sostendrá:

Estamos visualizando un Estado en el cual el ciudadano individual tiene derecho a tener voz efectiva en los asuntos colectivos. Es obvio, por descontado, que el poder que puede tener está limitado por las necesidades propias de la organización a gran escala. Pero aun así debería implicar que el hombre medio pueda elegir a sus gobernantes o ser elegido él mismo si puede. Debería implicar su derecho a realizar críticas sin restricciones. Debería involucrar el derecho a ser informado de todas las decisiones importantes y la oportunidad consecuente, en colaboración con sus conciudadanos, de revocar el mandato al gobierno (Laski, 1922, 14).

Aunque la conquista en 1918 bajo gobierno laborista de esa vieja demanda del movimiento obrero, el sufragio universal pleno, traería grandes esperanzas, Laski era consciente de que sus ideas sobre el poder todavía nadaban a contracorriente: "la práctica cojea dolorosamente por detrás de la teoría a la que se supone que tiene que sostener" (Laski, 1921, 228). Pero siguió defendiendo pese a ello sus principios libertarian:

Tengo como ciudadano un derecho ante la sociedad a realizarme de la mejor manera posible en común con los demás. Ese derecho implica que se me garanticen aquellas cosas sin las cuales no puedo, en los términos de Green, realizarme como un ser 
moral. (...) Tengo derechos para enriquecer la vida en común. Pero si estos derechos no consiguen hacerse realidad, entonces estoy legitimado para investigar al Estado bajo la hipótesis de que su voluntad no puede tener otro fin más allá de la consecución del bien común. Considero su poder como una fuerza ejercida con el fin de asegurar esos derechos. La catadura moral del Estado se me hace presente a través de los derechos que consigue garantizar (Laski, 1938 [1925], 39-40).

Otro gran exponente del socialismo libertarian de entreguerras fue G. D. H. Cole. Cole desarrolló una teoría de la "democracia funcional", donde las instituciones "políticas" se verían complementadas por otros organismos de representación derivados de los grupos que cumplían funciones esenciales en la sociedad (consumidores, productores, etc.). Sostuvo, además, que una sociedad democrática sería aquella en la que "el representado tendrá libre elección, contacto constante y considerable control sobre su representante", sin que esto supusiese convertir al representante en un mero delegado sometido al mandato imperativo (Cole, 1920, 32). Pero sin duda, la idea más relevante de su movimiento, el llamado "socialismo gremial", era su modelo de gestión empresarial:

El Guild Socialism sostiene que la gestión interna y el control de cada industria o servicio deben concederse, como un fideicomiso en nombre de la comunidad [as a trust on behalf of the community], en manos de los trabajadores que participan en ellos; pero defiende igualmente que se debe salvaguardar la representación y el punto de vista de los consumidores en relación con cada servicio (Cole, 1920, 39).

Esta posición se definía en contraposición a los socialistas "colectivistas" que renegaban de la industrial democracy, pero también frente a los "sindicalistas revolucionarios" (syndicalists) que renegaban del Estado (Cole, 1921, 32). Por eso, el socialismo gremial:

se propuso en contra tanto del socialismo de Estado como de lo que pronto había de ser llamado comunismo, y [lo hizo] para afirmar la importancia capital de la libertad del individuo y del grupo y la necesidad de extender la responsabilidad social a todo el mundo (...). Sostenían los socialistas gremiales que no era la pobreza, sino la esclavitud y la inseguridad los principales males que los obreros tenían que vencer. Verse libres del temor al desempleo, la libertad en el trabajo y el derecho a trabajar bajo inspectores y gerentes elegidos por ellos mismos y librar a los lugares de trabajo de jefes nombrados desde arriba, ya fuese por el patrono capitalista o por el Estado, esos eran los fundamentos necesarios de la democracia obrera, sin la cual la democracia política solo podía ser una ficción (Cole, 1975b [1954], 237).

\section{La New Left en la larga noche de la Guerra Fría}

La experiencia de la Segunda Guerra Mundial provocó la emergencia en Gran Bretaña de "un nuevo radicalismo popular" que permitió normalizar en la posguerra un sistema de intervención social y de controles de la economía por parte del Estado (Miliband, 1964, 272). Pero el estallido de la Guerra Fría y la alineación del Partido Laborista como socio promi- 
nente de los EEUU en el nuevo orden mundial reforzaron las ideas estatistas y tecnocráticas de su dirección -ese fabianismo que había fundamentado el modelo de nacionalizaciones de Herbert Morrison- y facilitaron la marginación de las ideas libertarian, que no tuvieron cabida en una época de ortodoxias ${ }^{12}$. Por su parte, el PCGB se mantuvo como un fiel aliado del estalinismo, ofreciendo la cara contraria de la moneda con su versión nativa del zhdanovismo, y cerrando filas e impidiendo el debate interno ante la crisis provocada por el "informe Jrushchov" y la invasión soviética que aplastó la Revolución húngara de 1956. Entre el comunismo estalinista y la socialdemocracia revisionista, trató de abrirse hueco el movimiento de la New Left, que recuperaría algunas viejas ideas sobre la libertad política.

La New Left (1959-1963) fue el resultado de la fusión de dos grupos de intelectuales. Por un lado, antiguos comunistas del PCGB que dejaron el partido tras los sucesos de 1956 (entre ellos E. P. Thompson y John Saville, que fundaron la revista The New Reasoner para "redescubrir los hilos democráticos y libertarian del comunismo británico suprimidos o silenciados durante los años de Stalin", Dworking, 1997, 108). Por el otro, un grupo de jóvenes socialistas vinculados a las universidades de Oxford y Cambridge, como Stuart Hall, Charles Taylor o Raphael Samuel, que crearían la revista Universities \& Left Review, y que se conocieron y empezaron a trabajar juntos gracias a su asistencia a los seminarios de postgrado de teoría e historia política que organizaba un viejo Cole en Oxford (Hall, 2010, 166).

Uno de los objetivos centrales del movimiento era descentralizar el poder político socializando y democratizando la propiedad, razón por la que la New Left Review acogió algunos debates claves que anticiparían la creación del famoso Institute for Workers Control de Ken Coates (Kenny, 1995, 46, 144).

Probablemente el mayor valedor de las ideas libertarian en la New Left fuera E. P. Thompson. Para Thompson, la New Left había “descubierto un lenguaje común” y "vislumbrado los mismos problemas para su análisis: el poder político y la degeneración burocrática, el poder económico y el control de los trabajadores, la descentralización y la participación popular en el control social” (“The New Left” en 2016 [1960], 290). Thompson entendió su propia posición política como la de un comunismo libertarian, esto es, uno que fuera "democrático y revolucionario tanto en sus medios, como en su estrategia y sus objetivos" (Thompson, 1978, 190).

Esta preocupación quedó especialmente recogida en sus escritos políticos de los años 70, cuando el movimiento de la primera New Left ya se había extinguido. Según Thompson, desde finales de los 60 muchas de las centenarias instituciones británicas que salvaguardaban la libertad política -como eran, por ejemplo, los juicios por jurado popular ("In Defence of the Jury", Thompson, 1994 [1986])- estaban siendo silenciosamente despedazadas por una operación a gran escala de políticos y medios de comunicación que representaban una ideología autoritaria y estatista. Thompson argumentó la necesidad de someter a estrictos controles democráticos las instituciones estatales como la policía, los servicios secretos o el ejército; criticó el puenteo del legislativo por parte del ejecutivo y denunció el blindaje

12 "La gente que habla demasiado, pronto se ve a sí misma en contra de ello. Harold Laski, por ejemplo. Un tipo brillante... pero empezó a dar discursos los fines de semana. Me tuve que deshacer de él. G.D.H. Cole fue otro tipo brillante. Una mente muy clara. Pero solía tener una nueva idea cada año, irrespetuoso de que los hombres ordinarios estuvieran interesados o no” (Clement Attlee, “¿Qué tipo de hombre llega a la cumbre?, Observer, 7 de febrero de 1960, citado en Thompson, 2016 [1960], 347-348). 
mediático de esta transformación autoritaria y anti-libertarian del Estado (véase especialmente "The State of the Nation" en Thompson, 1980). Por eso, en una de sus últimas intervenciones televisivas, recordó la esencia básica de la idea fiduciaria del poder, esta es, que "no es que nosotros existamos porque el Estado nos de permiso, es que el Estado existe para servirnos" (Channel Four, 1984).

Como apuntó la newlefter Dorothy Thompson, nunca existió una homogeneidad ideológica en la New Left, ni siquiera en torno a lo que significaba el socialismo (Thompson, 1996). No todos los miembros relevantes que pasaron por este movimiento compartían la formulación de Thompson de las ideas libertarian y fiduciarias. Para Ralph Miliband, por ejemplo:

El punto de partida de la teoría marxista de la política y el Estado es su rechazo categórico de esta visión del Estado como fiduciario [trustee], instrumento o agente de la "sociedad en su conjunto". Este rechazo se deriva necesariamente del concepto marxista de la sociedad como sociedad de clases. En las sociedades de clases, el concepto de "sociedad en su conjunto" y del "interés nacional" es claramente una mistificación (Miliband, 1977, 66).

\section{Conclusiones}

Los casos que he presentado aquí están lejos de agotar la historia completa de los libertarian socialists británicos. He expuesto tan solo las ideas de algunos personajes que considero fundamentales, dejando a un lado, por ejemplo, otros casos igualmente relevantes (como el comunismo frentepopulista) o un análisis sistemático de las relaciones particulares entre ellos. Pero las evidencias históricas nos deberían permitir sostener que esta corriente de ideas existió, aunque sus expresiones históricas siempre se dieron bajo formas mestizas y como respuestas concretas ante las transformaciones históricas del Estado y de la estructura de la propiedad. Un rasgo común define esencialmente esta corriente frente a sus rivales:

i) Delimitada por su izquierda, los libertarians no compartieron las nociones antipolíticas según las cuales, ya sea en la nueva sociedad socialista o también en la fase de transición a esta, podría prescindirse del Parlamento y de los magistrados (un impulso que, como hemos visto, era compartido por una parte del owenismo, por Morris en algunos momentos, o por los sindicalistas revolucionarios de entreguerras).

ii) Delimitada por su derecha, los socialistas libertarian de Gran Bretaña se opusieron tanto a los principios de autoridad y jerarquía arbitrarios, como a lo que consideraban una excesiva confianza en la delegación de poder (una figura que tomaba muchas formas: desde el gobernador paternalista de la comunidad owenita y el sectarismo de partido de Hyndman, hasta el fabianismo tecnócrata del Partido Laborista de posguerra o el despotismo interno de la dirección del PCGB).

Así, las ideas socialistas libertarian tuvieron que lidiar entre Escila y Caribdis, entre el apoliticismo y el estatismo. Aislar su núcleo conceptual nos permite delimitar, a su vez, el campo de juego de la teoría fiduciaria socialista, porque para que exista siquiera 
la posibilidad de plantear una fiduciarización del poder político hace falta que no se den ni un exceso de confianza en el representante ni tampoco una desconfianza absoluta hacia este: en ambos casos el mandato fiduciario se volvería superfluo. Por esta razón, y por la herencia conceptual que recibió la tradición socialista de la republicana (Domènech, 2019 [2004]; Gourevitch, 2014), el uso del lenguaje fiduciario no fue algo desconocido entre los socialistas libertarian, como se ha podido comprobar aquí.

Los whigs radicales Gordon y Trenchard señalaron a comienzos del siglo XVIII:

Mientras que el poder puede (y en la mayoría de las veces ocurre así) subsistir sin libertad, sin embargo, esta no puede subsistir sin él: así que se podría decir que la libertad tiene siempre al enemigo a las puertas (Trenchard y Gordon, 2018 [1720], \&33).

Para civilizar y domesticar a ese "enemigo" se alzaron los estandartes de muchos socialistas británicos, cuya existencia hace añicos la manida y estólida imagen del socialismo como una tradición que pone por encima el valor de la "igualdad" frente al de la "libertad". Como decía Harold Laski, desde el punto de vista socialista, "la libertad y la igualdad son inseparables" (Laski, 1925,9). Uno de esos estandartes libertarian, a veces recogido, a veces ondeando orgulloso, lucía el lenguaje fiduciario que los levellers y diggers habían popularizado siglos atrás. Quizá los estudiosos de las teorías fiduciarias puedan estar interesados en la historia de estos socialistas.

\section{Bibliografía empleada}

Blaazer, D. (1992), The Popular Front and the Progressive Tradition. Socialists, Liberals, and the Quest for Unity (1884-1939), Cambridge: Cambridge University Press.

Boaz, D. (2020), «Libertarianism», en Encyclopaedia Britannica (online): https://www. britannica.com/topic/libertarianism-politics.

Cole, G. D. H. (1920), Guild Socialism Re-Stated, Londres: Parsons.

Cole, G. D. H. (1921), Self-government in Industry, Londres: G. Bell.

Cole, G. D. H. (1975a [1952]), Historia del pensamiento socialista. Vol. I. Los precursores, México D.F.: Fondo de Cultura Económica.

Cole, G. D. H. (1975b [1954]), Historia del pensamiento socialista. Vol. III. La segunda internacional, 1889-1914, México D.F.: Fondo de Cultura Económica.

Criddle, E. J. y Fox-Decent, E. (2018) «Introduction», en Fiduciary Government, Cambridge: Cambridge University Press, pp. 1-17.

Díez del Corral, L. (1956), El liberalismo doctrinario, Madrid: Instituto de Estudios Políticos.

Domènech, A. (2019), El eclipse de la fraternidad. Una revisión republicana de la tradición socialista, Madrid: Akal.

Dryzek, J. S., Bonnie, H. y Phillips, A. (eds.), Oxford Handbook of Political Theory, Oxford: Oxford University Press.

Dunn, J. (1968), «The Identity of the History of Ideas». Philosophy, 43(164), pp. 85-104.

Dunn, J. (1984), The Politics of Socialism. An Essay in Political Theory, Cambridge: Cambridge University Press. 
Dworking, D. (1997), Cultural Marxism in Postwar Britain. History, the New Left and the Origins of Cultural Studies, Durham: Duke University Press.

Epstein, J. (1989), «Understanding the Cap of Liberty: Symbolic Practice and Social Conflict in Early Nineteenth-Century England», Past \& Present, 122, pp. 75-118.

Estlund, D. M. (2008), Democratic Authority. A Philosophical Framework, Princeton: Princeton University Press.

Foote, G. (1997), The Labour's Party Political Thought, Londres: Macmillan Press.

Goodway, D. (2006), Anarchist Seeds beneath the Snow. Left-Libertarian Thought and British Writers from William Morris to Colin Ward, Liverpool: Liverpool University Press.

Gourevitch, A. (2014), From Slavery to the Cooperative Commonwealth, Cambridge: Cambridge University Press.

Hall, S. (2010), «Vida y momentos de la primera nueva izquierda», New Left Review (Segunda Época), 61, pp. 163-182.

Hobsbawm, E. J. (2002), Interesting Times. A Twentieth-Century Life, Nueva York: Pantheon Books.

Kennedy, G. (2013), «Freemen, Free Labor, and Republican Discourses of Liberty in Early Modern England. Contributions to the History of Concepts», 8 (2), pp. 25-44.

Kenny, M. (1995), The First New Left. British Intellectuals after Stalin, Londres: Lawrence \& Wishart.

Laski, H. (1917), Studies on the Problem of Sovereignty, New Haven: Yale University Press.

Laski, H. (1921), The Foundations of Sovereignty, and other Essays, Nueva York: Harcourt, Brace \& Company.

Laski, H. (1925), Socialism and Freedom (Fabian Tract), Londres: Fabian Society.

Laski, H. (1938 [1925]), A Grammar of Politics, Londres: Billing \& Sons Ltd.

MacGilvray, E. (2011), The Invention of Market Freedom, Cambridge: Cambridge University Press.

Mack, E. (2011). «Libertarianism», en The Oxford Handbook of the History of Political Philosophy, Oxford: Oxford University Press, pp. 1-18.

Marshall, P. H. (1998), Demanding the Impossible. A History of Anarchism, Londres: Harper Perennial.

McCann, G. (1997), Theory and History. The Political Thought of E. P. Thompson, Aldershot: Ashgate.

Miliband, R. (1964), Parliamentary Socialism. A Study in the Politics of Labour, Nueva York: Monthly Review Press.

Miliband, R. (1977), Marxism and Politics, Oxford: Oxford University Press.

Morris, W. (2013), The Collected Works of William Morris. Vol. 23, Cambridge: Cambridge University Press.

Mundó, J. (2005), «Autopropiedad, derechos y libertad», en: Bertomeu, M. J. et al. (eds.), Republicanismo y democracia, Buenos Aires: Miño y Dávila, pp. 187-208.

Pettit, P. (1999), Republicanismo: una teoría sobre la libertad y el gobierno, Barcelona: Paidós.

Pettit, P. (2004), «Liberalismo y republicanismo», en Ovejero, F., Martí J. L. y R. Gargarella, R. (comps.), Nuevas ideas republicanas. Autogobierno y libertad, Barcelona: Paidós, pp. 115-135. 
Pocock, J. G. A. (1971), «Languages and Their Implications. The Transformation of the Study of Political Thought», en Politics, Languages and Time. Essays on Political Thought and History, Chicago: University of Chicago Press, pp. 3-41.

Rothbard, M. N. (2007), The Betrayal of the American Right, Auburn: Ludwig von Mises Institute.

Screpanti, E. (2007), Libertarian Communism. Marx, Engels and the Political Economy of Freedom, Basingstoke: Palgrave (MacMillan).

Shaw, G. B. (1893), The impossibilities of anarchism (Fabian Tract), Londres: Fabian Society.

Sprading, C. T. (1913), Liberty and the Great Libertarians, Los Ángeles: Golden Press.

Standing, G. (2018), La renta básica: un derecho para todos y para siempre, Barcelona: Pasado y Presente.

Stekloff, G. M. (1928), History of the First International, Londres: Martin Lawrence Lt.

Stevenson, S. W. (1889), A Dictionary of Roman Coins. Republican and Imperial, Londres: George Bell and Sons.

Thompson, D. (1996), «On the Trail of the New Left», New Left Review, 1(215), pp. 93-100.

Thompson, E. P. (1978), The poverty of theory and other essays, Londres: Merlin Press.

Thompson, E. P. (1979), «Recovering the libertarian tradition», Leveller Magazine, 22, pp. 20-22.

Thompson, E. P. (1980), Writing by the Candlelight, Londres: Merlin Press.

Thompson, E. P. (1988), William Morris. De romántico a revolucionario, Valencia: Ediciones Alfonso el Magnánimo.

Thompson, E. P. (1994), E. P. Thompson. Persons and Polemics, Londres: Merlin Press.

Thompson, E. P. (2012 [1963]), La formación de la clase obrera en Inglaterra, Madrid: Capitán Swing.

Thompson, E. P. (2016), E. P. Thompson. Democracia y socialismo, México, D.F.: Universidad Autónoma de México.

Torr, D. (1956), Tom Mann and his Times, Londres: Lawrence \& Wishart.

Trenchard, J. y Gordon, T. (2018 [1720-1723]), Cartas de Catón, Madrid: Agencia Estatal. Boletín Oficial del Estado.

Wolfe, D. M. (1944), Leveller Manifestoes of the Puritan Revolution, Londres: Thomas \& Nelson Sons. 
